\title{
Maximizing the phytochemical content and antioxidant activity of Ecuadorian brown rice sprouts through optimal germination conditions
}

Patricio J. Cáceres ${ }^{\mathrm{ab}}$, Cristina Martínez-Villaluenga ${ }^{\mathrm{b}}$, Lourdes Amigo ${ }^{\mathrm{c}}$ and Juana Frias ${ }^{\mathrm{b}}$

${ }^{a}$ Technical High School of the Litoral (ESPOL), Campus Gustavo Galindo Velasco, km 30,5 Vía Perimetral, 09-01-5863 Guayaquil, Ecuador.

${ }^{\mathrm{b}}$ Institute of Food Science, Technology and Nutrition (ICTAN-CSIC), Juan de la Cierva 3, 28006 Madrid, Spain.

${ }^{\mathrm{c}}$ Institute of Food Science Research, CIAL (CSIC-UAM), Nicolás Cabrera 9, Campus de Cantoblanco, 28049 Madrid, Spain.

\section{*Corresponding Author}

\section{Juana Frias}

E-mail address: frias@ictan.csic.es

Phone: + 34 912587510;

Fax: +34 915644853 


\section{ABSTRACT}

Germinated brown rice (GBR) is considered as alternative to white rice to fight against chronic diseases. Since functional quality of GBR depends on genotype and germination conditions, the objectives were to identify suitable Ecuadorian brown rice cultivars and optimal germination time and temperature to maximize $\gamma$-aminobutyric acid (GABA), total phenolics compounds (TPC) and antioxidant activity of GBR. Regression models for the prediction of phytochemical composition and antioxidant activity in GBR were also obtained. Germination improved GABA, TPC and antioxidant activity, in all cultivars. Maximum GABA and antioxidant activity were attained at $34^{\circ} \mathrm{C}$ for $96 \mathrm{~h}$, while the highest TPC was found at $28^{\circ} \mathrm{C}$ for $96 \mathrm{~h}$ in all cultivars. GBR cv. GO displayed the highest antioxidant activity and cv. 15 was more effective accumulating GABA and TPC in the optimal germination conditions. Therefore, Ecuadorian GBR could be used for the preparation of functional foods serving as preventative strategies in combating chronic diseases.

Keywords: Brown rice, germination, $\gamma$-aminobutyric acid, phenolic compounds, antioxidant activity, response surface methodology. 


\section{Introduction}

Rice is the most widely consumed cereal grain for a large part of the world's human population. Its production is the second-highest of the cereal worldwide after maize, (FAOSTAT, 2013). Rice is also the largest crop in Ecuador where long-grain varieties with greater resistance to diseases and pests, high yields and resistance to postharvest are mostly grown. Ecuadorian rice production is increasing gradually and, although rice is the staple food in this region, there has been an overproduction in 2010, and its is expectable this tendency for the coming years. Therefore, alternatives that diversify its application in human nutrition and improve its nutritional value are required.

Brown rice (BR) is composed of external thin layers (bran) that enclose the embryo and endosperm. The nutritional components in BR mainly exit in the germ and bran layers which are mostly removed as consequence of milling or polishing (Monks et al., 2013). For this reason, BR has higher nutritional quality than polished rice. Recently, human and animal studies have shown that consumption of BR reduces the risk of type-2 diabetes, cardiovascular disease (CVD) and cancer and these protective health effects have been linked to the presence of bioactive compounds such as polyphenols, GABA, acylated steryl $\beta$ glucoside and $\gamma$-oryzanol (Zhang et al., 2010; Kim, Kang, Nam, \& Friedman, 2012a; Goffman, \& Bergman, 2004).

Germination is a low-cost technology which starts with seed water uptake and ends at the protusion of radicle from the seed. Reactivation of metabolism occurs during seed germination process which results in the hydrolysis of storage proteins and carbohydrates and the synthesis/accumulation of metabolites with health-promoting properties. Germination of BR increases the content of $\gamma$-aminobutiric acid (GABA) and antioxidants such as phenolic compounds, $\gamma$-oryzanol and vitamin E among other bioactive compounds (Kim et al., 2012b). GABA exerts a series of health-promoting effects such as regulation of blood pressure and 
heart rate, alleviation of pain, anxiety and sleeplessness (Ito, 2004). In addition, GBR extract with enhanced levels of GABA stimulates immune cells (Oh, \& Oh, 2003) and it inhibits cancer cell proliferation (Oh and $\mathrm{Oh}, 2004)$. More recently, studies show that GABA is also a strong secratogue of insulin in the pancreas and effectively prevents diabetes (Imam, Azmi, \& Bhanger, \& Ismail, \& Ismail, 2012). Polyphenols have a wide range of biological activities which are linked to their protective effects on oxidative stress-induced diseases as it has shown in several epidemiological studies (Arts, \& Hollman, 2005). Recently, Esa, AbdulKadir, Amon, \& Azlan (2013) have demonstrated that attenuation of oxidative stress by germinated brown rice (GBR) consumption is reached through increases in antioxidant levels in plasma and antioxidant enzyme activity in the liver, thereby, preventing the formation of atherosclerotic plaques in hypercholesterolemic rabbits.

Accumulation of bioactive compounds during BR germination was shown to vary greatly depending on the cultivar, $\mathrm{pH}$, presence of additives and aeration of the soaking solution temperature and time during the phase of water uptake (also known as soaking or steeping), germination, and post-germination seedling growth (Watchararparpaiboon, Laohakunjit, \& Kerdchoechuen, 2010). These facts clearly indicate the relevance of cultivar selection and optimization of germination conditions before planning strategies of designing a functional food for improving consumer's health. Previous studies have focused on optimization of the germination process to maximize the nutritional quality of GBR (Rusydi, Noraliza, Azrina, \& Zulkhairi, 2011). So far, little has been reported about the optimization of soaking and germination conditions to produce GBR with improved phytochemical content and antioxidant activity. Thus, we have focused this work on the optimization of the phytochemical load (GABA and phenolic compounds) and antioxidant activity of sprouts from different commercial Ecuadorian BR cultivars. 
The objectives of the present study were to evaluate the effect of germination time and temperature of BR on potential health-promoting phytochemicals (GABA and TPC) and antioxidant activity to assess suitable rice cultivars and to optimize germination time and temperature in relation to concentrations of these bioactives and antioxidant activity in BR sprouts. Moreover, this study shows model equations that predict the phytochemical composition and antioxidant activity of BR sprouts based on germination time and temperature.

\section{Material and methods}

\subsection{Plant materials.}

Commercial certified BR cultivars INIAP 14, INIAP 15 and INIAP 17 (coded cv. 14, cv. 15, cv. 17) and experimental cultivar GO39839 (coded cv. GO) were provided by the National Autonomous Institute of Agricultural Research from Ecuador (Instituto Autónomo de Investigaciones Agropecuarias, INIAP). All varieties had similar harvest yields and seed apparence was translucent white center and extra-long grains.

2.2. Chemicals and reagents. Liquid chromatography (LC)-grade acetonitrile and methanol were purchased from Lab-Scan (Gliwice, Poland). Methanol analytical grade was provided by Scharlau (Barcelona, Spain). Other chemical reagents and standards used were purchased from Sigma-Aldrich (Steinheim, Germany). Water was purified using a Milli-Q system (Millipore Billerica, MA, USA).

\subsection{Seed germination.}

BR seeds of each cultivar ( $50 \mathrm{~g}$ ) were rinsed in distilled water and surface sterilized by $0.1 \%$ sodium hypochlorite (seed: $\mathrm{NaOCl}$ ratio, 1:5 w/v) for $30 \mathrm{~min}$ and drained. Afterwards, 
hygienized grains were rinsed with sterile distilled water to neutral $\mathrm{pH}$. Seeds were then placed in deionized water (seed:water ratio, 1:5 w/v) and soaked at $28^{\circ} \mathrm{C}$ for $24 \mathrm{~h}$. Soaking water was drained and seeds were placed on a drilled grille over moist filter. Seed were covered by moist filter paper and grille was placed in plastic germination trays containing distilled water. Germination trays containing hydrated rice seeds were introduced in a germination cabinet (model EC00-065, Snijders Scientific, Netherlands) provided with a water circulating system to keep $90 \%$ air humidity. Germination was carried out at 28 and 34 ${ }^{\circ} \mathrm{C}$ in darkness for 48 and $96 \mathrm{~h}$. Germination percentage was calculated as an estimation of seed viability and the germinated percentage was calculated from the following equation:

GP $=($ GBR seeds/total BR seeds $) \times 100$. GBR seeds were those with the radical projected from the embrio. Finaly, GBR samples were freeze-dried (Virtis Company, INC Gardiner, NY, USA), and homogeinized by using a ball mill (Glen Creston Ltd., Stanmore, UK). Powdered samples were stored in plastic bags, under vacuum, in darkness at $4{ }^{\circ} \mathrm{C}$ until further analysis. Each cultivar had three replications for each germination condition.

\subsection{Determination of $\gamma$-aminobutyric acid.}

The content of $\gamma$-aminobutyric acid (GABA) was determined using reversed-phase high performance liquid chromatography as described previously (Torino et al., 2013). Briefly, 0.5 $\mathrm{g}$ of sample was suspended in $12 \mathrm{~mL}$ distilled water. Suspension was stirred at $4{ }^{\circ} \mathrm{C}$ for $16 \mathrm{~h}$. Two independent extractions were performed for each replicate. Samples were centrifuged at $15000 \mathrm{rpm}$ at $10{ }^{\circ} \mathrm{C}$ for $20 \mathrm{~min}$. The supernatant was vaccum-dried and dissolved in $500 \mu \mathrm{L}$ of distilled water. A volume of $50 \mu \mathrm{L}$ of extract was added to $10 \mu \mathrm{L}$ of internal standard solution containing $1.2 \mathrm{mg} / \mathrm{mL}$ allyl-L-glycine and $20 \mu \mathrm{L}$ of $20 \%$ (v/v) triethylamine in $50 \%$ methanol $(\mathrm{v} / \mathrm{v})$. Mixtures were derivatized by adding $30 \mu \mathrm{L}$ of phenyl isothiocyanate. Subsequently, samples were vaccum-dried, reconstituted in $500 \mu \mathrm{L}$ of $0.1 \mathrm{M}$ ammonium 
acetate $\mathrm{pH} 6.5$ (mobile phase A) and centrifuged at $13000 \mathrm{rpm}$ at $10{ }^{\circ} \mathrm{C}$ for $5 \mathrm{~min}$. Supernatans were filtered through a $0.22 \mu \mathrm{m}$ nylon filter (Millipore Iberica, Madrid, Spain). HPLC analyses were performed with an Alliance Separation Module 2695 (Waters, Milford, USA), equipped with a photodiode array detector 2996 (Waters). Samples (20 $\mu$ L) were injected and compounds separation was carried out using a $\mathrm{C}_{18}$ Alltima ( 250 x $4.6 \mathrm{~mm}$ i.d., $5 \mu \mathrm{m}$ size) column (Grace \& Co., Albany, OR, USA) equipped with a guard column (Grace \& Co.), both thermostatted at $40{ }^{\circ} \mathrm{C}$. The chromatogram were developed at a flow rate of $0.7 \mathrm{~mL} / \mathrm{min}$ by eluting the sample in mobile phase $\mathrm{A}(0.1 \mathrm{M}$ ammonium acetate $\mathrm{pH} 6.5)$ and mobile phase B (0.1 M ammonium acetate, acetonitrile, methanol, 44/46/10, v/v/v, pH 6.5) as follows: isocratic flow 100\% A for 15 min, gradient flow from 100\% A to 100\% B for 27 min, isocratic flow 100\% B for 8 min, and finally column was equilibrated with 100\% A for 5 min. Data adquisition and integration was performed using Empower II softwate (Waters). GABA was identified by retention time and spiking the sample with a standard solution. GABA content was quantified by using a external GABA standard calibration curve with a linear range over $0-240 \mu \mathrm{g} / \mathrm{mL}$. Analyses were carried out in duplicate. The results were expressed in $\mathrm{mg}$ GABA/100 $\mathrm{g}$ of sample on dry matter basis (d.m.).

\subsection{Determination of total phenolic compounds.}

The content of total phenolic compounds (TPC) was analyzed using Folin-Ciocalteu's phenol reagent as described previously (Torino et al., 2013). Briefly, $0.5 \mathrm{~g}$ of sample were extracted in $10 \mathrm{~mL}$ of $80 \%(\mathrm{v} / \mathrm{v})$ methanol- $\mathrm{HCl}(1000 / 1)$ in distilled water by continuous magnetic stirring at room temperature for $16 \mathrm{~h}$. Two independent extractions were performed for each replicate. Extracts were centrifuged at $5000 \mathrm{rpm}$ at $5{ }^{\circ} \mathrm{C}$ for $5 \mathrm{~min}$. An aliquot of $100 \mu \mathrm{L}$ of diluted extract was mixed with $625 \mu \mathrm{L}$ distilled water, $250 \mu \mathrm{L} 7.5 \%$ (w/v) sodium carbonate and $25 \mu \mathrm{L}$ of $2 \mathrm{~N}$ Folin-Ciocalteu's phenol reagent. Reaction mixtures were vortexed and 
incubated in darkness at room temperature for $2 \mathrm{~h}$. The absorbance was measured at $739 \mathrm{~nm}$ in triplicated using a microplate reader (BioTek Instruments, Winooski, VT, USA) controlled by the Gene $5^{\mathrm{TM}}$ software version 1.1. (BioTek Instruments). A gallic acid standard curve with a linear range $(0-225 \mu \mathrm{g}$ gallic acid $/ \mathrm{mL})$ was prepared from a freshly made $1 \mathrm{mg} / \mathrm{mL}$ gallic acid stock solution. Results were expressed as mg of gallic acid equivalents (GAE) in $100 \mathrm{~g}$ of dry matter (d.m.).

\subsection{Determination of antioxidant activity.}

The antioxidant activity was analysed in the methanolic extracts previously obtained for TPC determination. Antioxidant activity was evaluated by the oxygen radical absorbance capacity (ORAC-FL) method previously described (Torino et al., 2013), with some modifications. The reaction was carried out at $37{ }^{\circ} \mathrm{C}$ in $75 \mathrm{mM}$ phosphate buffer $\mathrm{pH} 7.4$ for $150 \mathrm{~min}$. Reaction

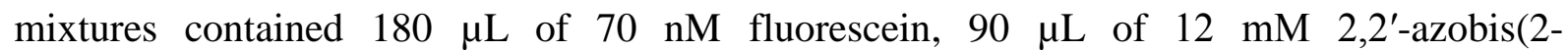
methylpropionamidine) dihydrochloride (AAPH) and $30 \mu \mathrm{L}$ of diluted sample or the standard Trolox at concentrations ranging from 1 to $8 \mu \mathrm{M}$. Reaction mixtures were placed in a black 96 well plate (Fisher Scientific) in triplicated. The plate was automatically shaken and the fluorescence was read in a microplate reader (Synergy HT, BioTek Instruments) every minute at $\lambda_{\text {exc }} 485 \mathrm{~nm}$ and $\lambda_{\text {emi }} 520 \mathrm{~nm}$. The equipment was controlled by Gene $5^{\mathrm{TM}}$ software, version 1.1. (BioTek Instruments). The areas under the fluorescence decay curve (AUC) based on relative fluorescence values to the initial reading were recorded and the AUC of blanks subtracted. Analyses were carried out in duplicate. Results were expressed as mg of Trolox equivalents (TE) in $100 \mathrm{~g}$ d.m.

2.7. Statistical analysis. Data shown are mean values of two determinations of each germination condition \pm standard deviation. Data were subjected to one-way analysis of 
variance (ANOVA) by Statgraphics Centurion XVI software, version 16.1.17 (Statistical Graphics Corporation, Rockville, Md). Differences between cultivars and germination conditions were compared by using a Duncan's multiple-range test at $P \leq 0.05$ probability levels.

To find out the optimum germination time and temperature for high antioxidant activity, GABA and TPC content in GBR, response surface approach was applied (Bezerra, Santelli, Oliveira, Villar, \& Escaleira, 2004). The response value Y was estimated by the following equation:

$$
\mathrm{Y}=\mathrm{b}_{0}+\mathrm{b}_{1} \mathrm{x}_{1}+\mathrm{b}_{2} \mathrm{x}_{2}+\mathrm{b}_{12} \mathrm{x}_{1} \mathrm{x}_{2}+\mathrm{b}_{11} \mathrm{x}_{1}^{2}+\mathrm{b}_{22} \mathrm{x}_{2}^{2}
$$

Where $\mathrm{Y}$ as the response variable; $\mathrm{x}_{1}$ and $\mathrm{x}_{2}$ as the independent variables representing germination time and temperature, respectively; $b_{0}$ as a constant coefficient; $b_{1}$ and $b_{2}$ as the linear coefficients; and $b_{12}, b_{11}$ and $b_{22}$ as the factor interaction coefficients. The model was simplified by removing no significant terms according to backward elimination technique (Mendenhall, \& Sincich, 1996).

\section{Results}

\subsection{Germination percentage.}

The present study shows that Ecuadorian BR cultivars GO, 14, 15 and 17 germinated effectively under the experimental conditions assayed. Soaking at $28{ }^{\circ} \mathrm{C}$ for $24 \mathrm{~h}$ and germination either at 28 and $34{ }^{\circ} \mathrm{C}$ of Ecuadorian BR cultivars resulted in germination percentages of $92-94 \%$ after 2 days and 96-98\% after 4 days (Figure 1). Moreover, no significant differences were observed in germination percentages among the Ecuadorian BR cultivars studied $(\mathrm{P} \geq 0.05)$. 
3.2. Effect of germination time and temperature on GABA content, TPC and antioxidant activity of sprouts from Ecuadorian BR cultivars.

Figure 2 shows the response surface plots of BR germination depending on the effects of temperature and time on GABA, TPC and antioxidant activity. The RSM was used to study the influence of two independent variables, temperature and time (24-120 h) in the germination process. Steeping time $(24 \mathrm{~h})$ was included in RSM plots as part of germination process. Three response variables were evaluated: GABA content, TPC and antioxidant activity. Response values for each set of variable combinations from GBR samples is presented in Tables 1-3. ANOVA was used to assess the main terms affecting responses; among them, time had a significant effect $(\mathrm{P} \leq 0.05)$ on all responses. Germination temperature had also a significant effect on GABA, TPC and antioxidant activity ( $\mathrm{P} \leq 0.05)$, with the exception of GABA for cv. GO and 14, and TPC for cv. GO. The predictive empirical models of the GABA and TPC formation and the antioxidant activity for sprouts of Ecuadorian BR cultivars is presented in Table 4. The results of the experiments are detailed below.

\subsubsection{Effect of germination time and temperature on GABA content.}

Table 1 shows the GABA content of ungerminated, soaked and GBR from four Ecuadorian cultivars. GABA content in ungerminated $B R$ was significantly different $(P \leq 0.05)$ among cultivars ranging from 4.3 to $8.3 \mathrm{mg}$ GABA/100g d.m. Raw BR cv. GO had the highest GABA compared with cultivars 14,15 and $17(\mathrm{P} \leq 0.05)$. Soaking process increased GABA levels from 1.3-fold in cv. GO to 3-fold in cv. 17.

GABA was accumulated in GBR throughout germination time in all cultivars (Table 1, Figure 2). Maximum GABA concentrations were found in 96 h-GBR in all cultivars $(\mathrm{P} \leq 0.05)$. GABA content of GBR was differently affected by germination temperature in studied cultivars. Additionally, temperature and time interacted significantly on GABA 
accumulation in cv. 15 and $17(\mathrm{P} \leq 0.05)$ (Table 4). Interestingly, germination at $28{ }^{\circ} \mathrm{C}$ conducted to higher GABA accumulation in 48h-GBR from cv. 15 and $17(\mathrm{P} \leq 0.05)$ compared with germination for $48 \mathrm{~h}$ at $34{ }^{\circ} \mathrm{C}$ (Table 1). GABA content in cv. GO and 14 germinated for 48h was not significantly affected $(\mathrm{P} \geq 0.05)$ by temperature (Table 1 , Figure 2$)$. Germination at $34{ }^{\circ} \mathrm{C}$ led to higher GABA concentrations in 96h-GBR cv. GO, 15 and $17(\mathrm{P} \leq 0.05)$ compared with germination at $28{ }^{\circ} \mathrm{C}$ for the same germination time (Table 1). However, temperature did not have a significant impact $(\mathrm{P} \leq 0.05)$ on GABA content of $96 \mathrm{~h}-\mathrm{GBR}$ from cv. 14. Finally, it is relevant to stress that GBR cv. 15 obtained at $34{ }^{\circ} \mathrm{C}$ for $96 \mathrm{~h}$ showed the highest GABA content (139.3 mg/100g d.m) (Table 1).

The response surface model showed that the optimum assayed conditions for GABA accumulation were obtained at the largest time $(120 \mathrm{~h})$ at $28^{\circ} \mathrm{C}$ for $\mathrm{cv} . \mathrm{GO}$ and 14 , and at 34 ${ }^{\circ} \mathrm{C}$ for cv. 15 and 17. The optimum predicted GABA concentration at these conditions was 115.7, 125.7, 135.5 and $122.3 \mathrm{mg} / 100 \mathrm{~g}$ d.m for cv. GO, 14, 15 and 17, respectively, which were not significantly different from those observed experimentally.

\subsubsection{Effect of germination time and temperature on TPC.}

Table 2 shows TPC of ungerminated, soaked and GBR from the four Ecuadorian cultivars studied. TPC in ungerminated BR was significantly $(\mathrm{P} \leq 0.05)$ higher in cultivars 14,15 and 17 (74-78 mg GAE/100g d.m) than in cultivar GO (58 mg GAE/100g d.m.). Soaking process slightly increased TPC in all BR cultivars $(\mathrm{P} \leq 0.05)$.

Germination brought about a noticeable increase in TPC $(\mathrm{P} \leq 0.05)$, being this effect time-dependent in all cultivars studied (Table 2, Figure 2). In this sense, TPC increased up to 2 and 4-fold in BR germinated for 48 and 96 h, respectively. Moreover, germination temperature significantly influenced TPC accumulation in all GBR cultivars $(\mathrm{P} \leq 0.05)$ (Table 2, Figure 2). Moreover, temperature and time interacted significantly on TPC accumulation in 
cv. 14,15 and $17(\mathrm{P} \leq 0.05)$ (Table 4). BR germinated for $48 \mathrm{~h}$ showed a higher TPC at $34{ }^{\circ} \mathrm{C}$ (127.8-150.1 mg GAE/100g d.m.) than at $28^{\circ} \mathrm{C}(108-129 \mathrm{mg}$ GAE/100g d.m.) $(\mathrm{P} \leq 0.05)$. Inversely, 96h-GBR exhibited higher TPC at $28{ }^{\circ} \mathrm{C}(207.6-306.6 \mathrm{mg}$ GAE/100g d.m.) than at $34{ }^{\circ} \mathrm{C}(193.7-259.7 \mathrm{mg} \mathrm{GAE} / 100 \mathrm{~g}$ d.m.) $(\mathrm{P} \leq 0.05)$. Finally, it is worthy to emphasize that the highest TPC was observed for GBR cv. 15 obtained at $28{ }^{\circ} \mathrm{C}$ for $96 \mathrm{~h}(306.6 \mathrm{mg} \mathrm{GAE} / 100 \mathrm{~g}$ d.m).

The response surface model showed that the optimum evaluated conditions for TPC accumulation during germination were at temperatures of aproximately $28{ }^{\circ} \mathrm{C}$ and the largest processing time $(120 \mathrm{~h})$. The optimum predicted TPC concentration at these conditions was 246.8, 204.8, 298.0, $267.7 \mathrm{mg}$ GAE/100g d.m for cv. GO, 14, 15 and 17, respectively, which were quite similar to those experimentally obtained.

\subsubsection{Effect of germination time and temperature on antioxidant activity.}

Antioxidant activity of ungerminated, soaked and GBR from the four studied Ecuadorian cultivars is presented in Table 3. Among the BR cultivars, antioxidant activity differed greatly and the highest levels corresponded to cv. 14 and 17 (311.4 and $316.8 \mathrm{mg}$ TE/100g d.m., respectively), followed by cv. 15 (291.7 mg TE/100g d.m.), and cv. GO (242.7 mg TE/100g d.m.) $(\mathrm{P} \leq 0.05)$. Antioxidant activity of soaked BR was not statistically different from raw BR, with exception of cv. 14 in which a slight although significan increase was observed $(\mathrm{P} \leq 0.05)$. Germination time directly affected the antioxidant activity of BR sprouts (Table 3, Figure 2). Antioxidant activity of GBR increased prominently with larger germination time (P $\leq 0.05$ ). ORAC values were up to 2-fold and 4-fold higher after sprouting of BR for 48 and 96 h, respectively (Table 3). Among cultivars, antioxidant activity also varied greatly following sprouting at different germination temperatures (Table 3, Figure 2). In addition, temperature and time interacted significantly on antioxidant activity in all BR cultivars $(\mathrm{P} \leq 0.05)$ (Table 4). 
Thus, both $48 \mathrm{~h}$ and $96 \mathrm{~h}-$ GBR samples presented higher antioxidant capacity at $34{ }^{\circ} \mathrm{C}$ than at $28^{\circ} \mathrm{C}(\mathrm{P} \leq 0.05)$ (Table 3). Among all of the sprouted BR tested, $96 \mathrm{~h}-\mathrm{GBR}$ produced at $34^{\circ} \mathrm{C}$ showed the highest antioxidant activity (1054.7 mg TE/100g d.m.) (Table 3).

The response surface model showed that the best germination studied condition to maximize antioxidant activity in rice sprouts were temperatures of aproximately $34{ }^{\circ} \mathrm{C}$ and the largest time $(120 \mathrm{~h})$. The optimum predicted antioxidant activity at these conditions was 1032.0, 925.6, 739.7, 686.8 mg TE/100g d.m. for cv. GO, 14, 15 and 17, respectively, which did not differ significantly from those experimentally observed.

\section{Discussion}

White rice is the staple food for most of the people in low- and middle-income regions of the world. In these regions, growing incidence and prevalence of chronic diseases such as type-2 diabetes have been linked to white rice consumption (Hu, Palik, \& Sun, 2012). Prolonged consumption of white rice may lead to other disorders like obesity, glucose intolerance and cardiovascular disease due to its high glycemic index. Recently, consumption of BR is gaining popularity among health concious consumers due to its lower glycemic index (Palasangui, \& Thompson, 2006) and it can be considered a challenge to reduce the risk of disease in those world regions. To our knowledge the present work is the first report on characterization of phytochemical content (GABA and TPC) and antioxidant potential of Ecuadorian BR cultivars. Interestingly, total phenolic content of Ecuadorian BR cultivars studied here was higher to recent reported data for Asian non-pigmented BR varieties (Huang, \& $\mathrm{Ng}, 2012$ ) which suggest their potential as promising cultivars for development of healthy food.

Nevertheless, a existing limitation for the consumption of BR is its lower organoleptic quality (poor texture, off putting bran odor), low digestibility and not easy to cook 
characteristic. Germination appears as an open stratey to improve the organoleptic quality of BR and, besides, it provides additional increases in the content of bioactive compounds (Donkor, Stojanowska, Ginn, Ashton, \& Vasiljevic, 2012). Therefore, GBR might be a quick and cost-effective alternative to reduce the risk of chronic disease in the developing world without altering the existing consumption habits.

Germination percentage of rough rice (whole kernell and grain) seems to be more effective than germination of BR (Moongngarm, \& Saetung, 2010), however rough rice sprouts result abrasive and hardly edible. Therefore, germination of BR is preferable and dehusking should be carried out in the way of not causing detrimental effect on germination yield. It is worth noting that GBR could be produced not only by industrial sector but also in the household by soaking BR grains in water and further sprouting, which is a more affordable alternative for low and middle income regions.

Temperature is a key point to germinate BR grains. Most of the scientific studies on germinated rice have been carried out at temperatures of producers` countries (between 28 and $34{ }^{\circ} \mathrm{C}$ ). However, a systematic study comparing germination percentages at such temperatures in different BR varieties had not been carried out so far. In this sense, the present study shows that Ecuadorian BR cultivars GO, 14, 15 and 17 germinated effectively under the experimental conditions assayed (germination percentage $>90 \%$ ). These results are higher than those found in the literature for BR cultivar RD-6 (84.3\%) (Moongngarm, \& Saetung, 2010), differences that could be explained due to the germination rate seems to be influenced by several factors such as the amount of water added and soaking time. In addition, temperature has a profound effect on germination by affecting the metabolic reactivation and postgermination growth of the sprout. Yoshida (1981) showed that to reach $90 \%$ germination, longer times of incubation are needed at $15^{\circ} \mathrm{C}$ compared with incubation at 
temperatures ranging from 25 to $40{ }^{\circ} \mathrm{C}$, however no further studies have been conducted so far.

Phytochemical quality of sprouts depends on many factors such as genotype, steeping and germination conditions. This means that optimum conditions need to be defined for individual cereal cultivars to improve the functional quality of the sprout. Therefore, our primary goal was to establish those germination conditions conducting to the highest concentration of GABA, TPC and antioxidant activity in four ecuadorian BR cultivars by the RSM.

The results of the present study showed that GABA accumulation was initiated in the soaking process and continued in a time-dependent manner during germination in all cultivars. These results are in accordance with previous studies (Sen, Tewu, Lijun, \& Shanbai, 2008). This can be explained by the fact that soaking process induces glutamate decarboxylase (GAD) activity which increases with germination time. GAD catalyses the $\gamma$ decarboxylation of L-glutamic acid to carbon dioxide and GABA. In addition, it has been reported recently that GABA could be formed from putrescine during the response to abiotic stress (Shelp, Bozzo, Trobacher, Zarei, Deyman, \& Brikis, 2012). Moreover, cultivar differences in GABA accumulation have been reported during water soaking of ten rice varieties (Saikusa, Horino, \& Mori, 1994). Our results also show for the first time that germination temperature affected differently the GABA accumulation rate depending on cultivar. GABA accumulation was slowed down at $34{ }^{\circ} \mathrm{C}$ compared to $28{ }^{\circ} \mathrm{C}$ in cv. 15 and 17 whereas this effect was not found for $\mathrm{cv}$. GO and 14. The highest GABA concentrations in sprouts were observed at higher temperatures $\left(34{ }^{\circ} \mathrm{C}\right)$ which is in consistency with studies showing that GAD activity in rice increase with increasing temperatures from 20 to $40{ }^{\circ} \mathrm{C}$ (Yang, Yin, Guo, \& Gu, 2013). Interestingly, GABA content of Ecuadorian varieties of 96 hGBR was higher than that found in the literature for 181 Asian varieties ranging from 34.6 to 
$87.8 \mathrm{mg} \mathrm{GABA} / 100 \mathrm{~g}$ d.m. (Sen et al., 2008). It is accepted that daily intake of $20 \mathrm{mg}$ GABA is able to prevent moderate hypertension in adults (Tsuchida et al., 2003). Therefore, $\sim 25 \mathrm{~g}$ of GBR (d.m) obtained in this study would provide enough GABA content to contribute on such effect. Nevertheless, future animal experiments should be performed to confirm that consumption of GBR have an antihypertensive effect.

BR seems to be a good source of phenolic compounds and our results are within the range of previously reported data of non-pigmented BR varieties being the predominant phenols $p$-coumaric and ferulic acids, however, the phenolic composition of BR may vary among genotypes (Huang, \& Ng, 2012). Similarly to GABA, TPC increased dramatically as consequence of soaking and germination regardless of cultivar, results which are in agreement with information provided by other authors (Moongngarm, Saetung, 2010). Phenolic compounds increase found in BR may be explained due to germination induces enzyme expression/activation of the phenylpropanoid pathway and the hydrolysis of cell wall polysaccharides that cause the release of cell wall-bound phenolics (He, Han, Yao, Shen, \& Yang, 2011). This is supported by Tian, Nakamura, \& Kayahara, (2004) that showed an increase in free phenolic acids (ferulic, $p$-coumaric, and sinapic acids) and hydrolysable phenolic compounds, as well as decreases in the hydroxycinnamate sucrose esters in GBR. In the present work, the highest amounts of TPC were observed at germination temperature of $28{ }^{\circ} \mathrm{C}$ for $96 \mathrm{~h}$. Lower TPC was observed in GBR at $34{ }^{\circ} \mathrm{C}$ in all cultivars. These results could be due to increases in the activity of enzymes responsible for the oxidation of endogenous phenolic compounds and phenolic-containing biomolecules such polyphenol oxidases (PPO) and peroxidases (POX). This hypothesis is supported by studies in which PPO activity was increased with higher temperatures during sprouting of wheat (Gupta, Agarwal, Agarwal, Nathawat, Gupta, \& Singh, 2013). Moreover, optimum germination conditions $\left(28^{\circ} \mathrm{C}, 96 \mathrm{~h}\right)$ gave rise to greater TPC than those reported in previous studies (Moongngarm, \& Saetung, 
2010). Additionally, we observed that TPC was differently affected by germination temperature depending on cultivar, results that have not been reported so far.

With regard to antioxidant activity, it is worth noting that germination brought about an enhancement of the antioxidant potential of BR, in agreement with previous studies (Tian et al., 2004). Antioxidant activity of BR during germination was time and temperature dependent. This effect could be explained to higher accumulation of compounds with peroxyl-scanvenging activity such as phenolic compounds (Andriantsitohaina et al., 2012). TPC was positively correlated with antioxidant activity in all cultivars studied $(\mathrm{P} \leq 0.05)$ which supports this hypothesis. In consistency with this observation, some reports have demonstrated that GBR display higher antioxidant capacity due to hydrolytic enzymes may release free phenolics with more effective antioxidant activity (Tian et al., 2004). Moreover, it has been reported that germination under high temperature $\left(42{ }^{\circ} \mathrm{C}\right)$ induced several radical scavenging enzymes such as superoxide dismutases, gluthatione S-transferase, catalase, peroxidases, and enzymes in the ascorbate-glutathione cycle to keep a balance of redox homeostasis (Gupta et al., 2013). The GBR obtained in this study is a valuable source of natural antioxidants that most likely can positively influence the overall antioxidant status in humans. A recent study have demonstrated that GBR supplementation increases antioxidant enzyme activity and reduces lipid peroxidation in hypercholesterolemic rabbits (Esa et al., 2013). Predicted antioxidant activity in GBR obtained under optimum germination conditions $\left(34{ }^{\circ} \mathrm{C}\right.$ for $96 \mathrm{~h}$ ) ranged from 687 to $1032 \mathrm{mg}$ TE/100g d.m. among cultivars. These results on antioxidant activity provide added value to GBR to enrich bakery products, as it has been recently incorporated to wheat flour for the production of chapatti-bread with enhanced antioxidant activity (Gujral, Sharma, Bajaj, \& Solah, 2012). 


\section{Conclusion}

Germination led to improvements in the GABA and TPC concentrations and antioxidant activity of BR. Optimal germination conditions for accumulation of GABA and antioxidant activity were obtained after soaking at $28^{\circ} \mathrm{C}$ for $24 \mathrm{~h}$ followed by germination at $34{ }^{\circ} \mathrm{C}$ for 96 h, while the highest TPC was found in GBR obtained at $28{ }^{\circ} \mathrm{C}$ for $96 \mathrm{~h}$. BR cv.GO was more effective accumulating antioxidants with peroxyl-scavenging activity (predicted value 1032 mg TE/100g d.m.), while cv. 15 was more effective accumulating GABA (predicted value $135.5 \mathrm{mg} / 100 \mathrm{~g}$ d.m.) and TPC (298 mg GAE/100g d.m.) under the optimal germination conditions. These germinated grains with improved levels of bioactive compounds can be consumed as direct food or incorporated to staple foods, and to be offered as preventative food strategies in combating chronic diseases.

\section{Acknowledgements}

This work was financially supported by AGL2010-16310 project from the Ministry of Science and Innovation (MICINN, Spain). P. J. Caceres is indebted to the Ministry of High Education, Science, Technology and Innovation (SENESCYT, Ecuador) for the foreign Ph.D. grant. We also acknowledge to National Autonomous Institute of Agricultural Research from Ecuador (INIAP) for providing the BR cultivars.

\section{References}

Andriantsitohaina, R., Auger, C., Chataigneau, T., Etienne-Selloum, N., Li, H., Martínez, M. C., Schini-Kerth, V. B., \& Laher, I. (2012). Molecular mechanisms of the cardiovascular protective effects of polyphenols. British Journal of Nutrition, 108, 1532-1549.

Arts, I. C., \& Hollman, P.C. (2005).Polyphenols and disease risk in epidemiologic studies. American Journal of Clinical Nutrition, 81, 317S-325S. 
Bezerra, M. A., Santelli, R. E., Oliveira, E. P., Villar, L. S., \& Escaleira, L. A. (2012). Response surface methodology (RSM) as a tool for optimization in analytical chemistry. Talanta, 76, 965-977.

Donkor, O. N., Stojanowska, L., Ginn, P., Ashton, J., \& Vasiljevic, T. (2012). Germinated grains-Sources of bioactive compounds. Food Chemistry, 135, 950-959.

Esa, N.M., Abdul-Kadir, K-K., Amon, Z., \& Azlan, A. (2013). Antioxidant activity of white rice, brown rice and germinated brown rice (in vivo and in vitro) and the effects on lipid peroxidation and liver enzymes in hyperlipidaemic rabbits. Food Chemistry, 141, 13061312.

FAOSTAT. Food and Agricultural Organization from the United Nations. (2013). (http://faostat.fao.org/site/339/default.aspx). Last accessed August 22, 2013.

Goffman, F., \& Bergman, C. J. (2004). Rice kernell phenolic content and its relationship with antiradical efficiency. Journal of the Science of Food and Agriculture, 84, 1235-1240.

Gujral, H. S., Sharma, P., Bajaj, R., \& Solah, V. (2012). Effect of incorporating germinated brown rice on the antioxidant properties of wheat flour chapatti. Food Science and Technology International, 18, 47-54.

Gupta, N. K., Agarwal, S., Agarwal, V. P., Nathawat, N. S., Gupta, S., \& Singh, G. (2013). Effect of short-term heat stress on growth, physiology and antioxidative defence system in wheat seedlings. Acta Physiologiae Plantarum, 35, 1837-1842.

He, D., Han, C., Yao, J., Shen, S., \& Yang, P. (2011). Constructing the metabolic and regulatory pathways in germinating rice seeds through proteomic approach. Proteomics, 11, 2693-2713.

Hu, E. A., Palik, P. V., \& Sun, Q. (2012). White rice consumption and risk of type 2 diabetes: meta-analysis and systematic review. British Medical Journal, 344: e1454, 1-9. 
Huang, S-H., \& Ng, L-T. (2012). Quantification of polyphenolic content and bioactive constituents of some commercial rice varieties in Taiwan. Journal of Food Composition and Analysis, 26, 122-127.

Imam, M. U., Azmi, N. H., Bhanger, M. I., Ismail, N., \& Ismail, M. Antidiabetic properties of germinated brown rice: A systematic review. (2012) Evidence-Based Complementary and Alternative Medicine, Article ID 816501, 1-12.

Ito, S. (2004). Marketing of value-added rice products in Japan: germinated brown rice and rice bread. Food Agricultural Organization FAO rice conference, Rome Italy, http://www.fao.org/rice2004/en/pdf/ito.pdf, last accessed August 22, 2013.

Kim, S. P., Kang, M. Y., Nam, S. H., \& Friedman, M. (2012a).Dietary rice component $\gamma$ oryzanol inhibits tumor growth in tumor-bearing mice. Molecular Nutrition and Food Research, 56, 935-944.

Kim, H-Y., Hwang, I. G., Kim, T. M., Woo, K. S., Park, D. S., Kim, J. H., Kim, D. J., Lee, J., Lee Y. R., \& Jeong, H. S. (2012b). Chemical and functional components in different parts of rough rice (Oryza sativa L.) before and after germination. Food Chemistry, 134, 288-293.

Mendenhall, W., \& Sincich, T. (1996). A second course in Statistics: Regresion analysis (pp. 899). New Jersey: Prentice Hall Inc.

Monks, J.L.F., Levien-Vanier, N., Casaril, J., Manica-Berto, R., de Oliveira, M., BaptistaGomes, C., Peres de Carvalho, M., Guerra-Dias, A. R., \& Cardoso-Elias, M. (in press). Effects of milling on proximate composition, folic acid, fatty acids and technological properties of rice. Journal of Food Composition and Analysis, doi: 10.1016/j.jfca.2013.01.009).

Moongngarm, A., \& Saetung, N. (2010). Comparison of chemical compositions and bioactive compounds of germinated rough rice and brown rice. Food Chemistry 122, 782-788. 
Oh, C. H., \& Oh, S. H. (2004). Effects of germinated brown rice extract with enhanced levels of GABA of cancer cell proliferation and apoptosis. Journal of Medical Food, 7, 19-23.

Oh, S. H., \& Oh, C. H. (2003). Brown rice extracts with enhanced levels of GABA stimule immune cells. Food Science and Biotechnology, 12, 248-252.

Palasangui, L. N., \& Thompson, I. U. (2006). Bood glucose lowering effects of brown rice in normal and diabetic subjects. International Journal of Food Science and Nutrition, 57, $151-158$.

Rusydi, M., Noraliza, C. W., Azrina, A., \& Zulkhairi, A. (2011). Nutritional changes in germinated legumes and rice varieties. International Food Research Journal, 18, 705713.

Saikusa, T., Horino, T., \& Mori, Y. (1994). Accumulation of $\gamma$-aminobutyric acid (GABA) in the rice germ during water soaking. Bioscience, Biotechnology and Biochemistry, 58, $2291-2292$.

Sen, Y., Tewu, Y., Lijun, Z. H., \& Shanbai, X. (2008). The variation of $\gamma$-aminobutyric acid content in germinated brown rice among different cultivars. Scientia Agricultura Sinica, 41, 3974-3982.

Shelp, B. J., Bozzo, G. G., Trobacher, C. P., Zarei, A., Deyman, K. L., \& Brikis, C. J. (2012). Hypothesis/review: contribution of putrescine to 4-aminobutyrate (GABA) production in response to abiotic stress. Plant Science, 193-194, 130-135.

Tian, S., Nakamura, K., \& Kayahara, H. (2004). Analysis of phenolic compounds in white rice, brown rice and germinated brown rice. Journal of Agricultural and Food Chemistry, 52, 4808-4813.

Torino, M. I., Limón, R. I., Martínez-Villaluenga, C., Mäkinen, S., Pihlanto, A., VidalValverde, C., \& Frias, J. (2013). Antioxidant and antihypertensive properties of liquid and solid state fermented lentils. Food Chemistry, 136, 1030-1037. 
Tsuchida, T., Mashiko, K., Yamada, K., Hiratsuka, H., Shimada, T., Itagaki, Y., Fujinuma, H., Samejima, K., Nakamura, T., Hasegawa, T., \& Matsubayashi, T. (2003). Clinical study of $\gamma$-aminobutyric acid-rich Chlorella for subjects with high-normal blood and mild- hypertension. Journal of Japanese Society of Nutrition and Food Science, 56, 97102.

Watchararparpaiboon, W., Laohakunjit, N., \& Kerdchoechuen, O. (2010). An improved process for high quality and nutrition of brown rice production. Food Science and Technology International, 16, 147-158.

Yang, R., Yin, Y., Guo, Q., \& Gu, Z. (2013). Purification, properties and cDNA cloning of glutamate decarboxylase in germinated faba bean (Vicia faba L.). Food Chemistry, 138, 1945-1951.

Yoshida, S. (1981). Growth and development of the rice plant. In S. Yoshida (Eds.). Fundamentals of rice crop Science (pp. 1-9). Los Baños, Phillipines: The international rice Research Institute.

Zhang, G., Malik, V.S., Pan, A., Kumar, S., Holmes, M. D., Spiegelman, D., Lin, X., \& Hu, F. B. (2010). Substituting brown rice for white rice to lower diabetes risk: A focusgroup study in Chinese adults. Journal of the American Dietetic Association, 110, 12161221. 
Figure 1. Germination percentage of Ecuadorian BR cultivars at different temperatures (28 and $34^{\circ} \mathrm{C}$ ) and time (48 and $\left.96 \mathrm{~h}\right)$. Values are the mean of three replicates. Bars indicate the standard deviation.

Figure 2. Response surface plots of germination of Ecuadorian BR cultivars (GO, 14, 15 and 17) showing the effects of temperature and time on GABA content, TPC and antioxidant activity. 
Table 1. GABA content (mg/100g d.m.) in ungerminated, soaked and germinated grains of four Ecuadorian brown rice cultivars (GO, 14, 15, 16 and 17)

\begin{tabular}{lcccccc}
\hline Treatment & Temperature $\left({ }^{\circ} \mathrm{C}\right)$ & Time $(\mathrm{h})$ & $\mathrm{GO}$ & 14 & 15 & 17 \\
\hline Ungerminated grain & --- & --- & $8.26 \pm 0.67^{\mathrm{a}}{ }_{\mathrm{C}}$ & $4.34 \pm 0.18^{\mathrm{a}}{ }_{\mathrm{A}}$ & $4.69 \pm 0.35^{\mathrm{a}}{ }_{\mathrm{AB}}$ & $5.07 \pm 0.41^{\mathrm{a}}{ }_{\mathrm{B}}$ \\
Soaking & 28 & 24 & $10.70 \pm 1.05^{\mathrm{b}}{ }_{\mathrm{C}}$ & $7.97 \pm 0.45^{\mathrm{b}}{ }_{\mathrm{A}}$ & $9.18 \pm 0.69^{\mathrm{b}}{ }_{\mathrm{B}}$ & $16.69 \pm 0.69^{\mathrm{b}}{ }_{\mathrm{D}}$ \\
Germination & 28 & 48 & $80.70 \pm 1.28^{\mathrm{c}}{ }_{\mathrm{BC}}$ & $70.81 \pm 4.04^{\mathrm{c}}{ }_{\mathrm{A}}$ & $83.14 \pm 0.79^{\mathrm{d}}{ }_{\mathrm{C}}$ & $77.66 \pm 2.26^{\mathrm{d}}{ }_{\mathrm{B}}$ \\
& 28 & 96 & $107.48 \pm 2.04^{\mathrm{d}}{ }_{\mathrm{A}}$ & $122.78 \pm 5.23^{\mathrm{d}}{ }_{\mathrm{B}}$ & $124.43 \pm 6.02^{\mathrm{e}}{ }_{\mathrm{B}}$ & $102.26 \pm 5.12^{\mathrm{e}}{ }_{\mathrm{A}}$ \\
& 34 & 48 & $76.66 \pm 3.66^{\mathrm{c}}{ }_{\mathrm{D}}$ & $62.56 \pm 2.60^{\mathrm{c}}{ }_{\mathrm{C}}$ & $54.22 \pm 3.05^{\mathrm{c}}{ }_{\mathrm{B}}$ & $44.63 \pm 1.33^{\mathrm{c}}{ }_{\mathrm{A}}$ \\
& 34 & 96 & $123.92 \pm 5.94^{\mathrm{e}}{ }_{\mathrm{A}}$ & $127.98 \pm 10.07^{\mathrm{d}}{ }_{\mathrm{A}}$ & $139.32 \pm 5.75^{\mathrm{f}}{ }_{\mathrm{B}}$ & $129.47 \pm 6.08^{\mathrm{f}}{ }_{\mathrm{AB}}$ \\
& & & & & &
\end{tabular}

Data are the mean values \pm standard deviation of three independent experiments $(\mathrm{n}=3)$. Different lowercase letters indicate significant difference among mean values within a column ( $\mathrm{P} \leq 0.05$ according to Duncan's test). Different capital letters indicate significant difference among mean values within a row ( $\mathrm{P} \leq 0.05$ according to Duncan's test). 
Table 2. Total phenolic content (mg GAE/100g d.m.) in ungerminated, soaked and germinated grains of four Ecuadorian brown rice cultivars (GO, 14, 15, 16 and 17)

\begin{tabular}{|c|c|c|c|c|c|c|}
\hline Treatment & Temperature $\left({ }^{\circ} \mathrm{C}\right)$ & Time (h) & GO & 14 & 15 & 17 \\
\hline Ungerminated grain & --- & -- & $57.65 \pm 2.49^{\mathrm{a}}{ }_{\mathrm{A}}$ & $77.84 \pm 5.37^{\mathrm{a}}{ }_{\mathrm{B}}$ & $76.85 \pm 3.78^{\mathrm{a}}{ }_{\mathrm{B}}$ & $73.52 \pm 3.13^{\mathrm{a}}{ }_{\mathrm{B}}$ \\
\hline Soaking & 28 & 24 & $66.61 \pm 4.01_{\mathrm{A}}^{\mathrm{b}}$ & $81.63 \pm 2.71^{\mathrm{b}}{ }_{\mathrm{B}}$ & $99.73 \pm 3.55^{\mathrm{b}}{ }_{\mathrm{C}}$ & $81.73 \pm 2.54^{\mathrm{b}}{ }_{\mathrm{B}}$ \\
\hline \multirow[t]{4}{*}{ Germination } & 28 & 48 & $114.04 \pm 5.08^{c}{ }_{B}$ & $108.96 \pm 6.39^{\mathrm{c}}{ }_{\mathrm{AB}}$ & $129.57 \pm 4.99^{c}{ }_{C}$ & $103.64 \pm 7.18^{\mathrm{c}}{ }_{\mathrm{A}}$ \\
\hline & 28 & 96 & $252.16 \pm 4.42^{\mathrm{f}}{ }_{\mathrm{B}}$ & $207.61 \pm 7.90_{\mathrm{A}}^{\mathrm{f}}$ & $306.65 \pm 9.98_{D}^{f}$ & $286.73 \pm 7.57^{\mathrm{f}}{ }_{\mathrm{C}}$ \\
\hline & 34 & 48 & $133.38 \pm 2.53^{\mathrm{d}}{ }_{B}$ & $127.86 \pm 6.28^{\mathrm{d}}{ }_{A}$ & $150.10 \pm 4.04^{\mathrm{d}}{ }_{\mathrm{C}}$ & $150.10 \pm 2.59^{\mathrm{d}}{ }_{\mathrm{C}}$ \\
\hline & 34 & 96 & $241.40 \pm 3.25^{\mathrm{e}}$ & $193.68 \pm 8.08_{\mathrm{A}}^{\mathrm{e}}$ & $259.72 \pm 9.19^{\mathrm{e}}{ }_{\mathrm{D}}$ & $213.02 \pm 5.60^{\mathrm{e}}{ }_{\mathrm{B}}$ \\
\hline
\end{tabular}

Data are the mean values \pm standard deviation of three independent experiments $(n=3)$. Different lowercase letters indicate significant difference among mean values within a column $(\mathrm{P} \leq 0.05$ according to Duncan's test). Different capital letters indicate significant difference among mean values within a row (P $\leq 0.05$ according to Duncan's test). 
Table 3. Antioxidant activity (mg TE/100g d.m.) in ungerminated, soaked and germinated grains of four Ecuadorian brown rice cultivars $($ GO, 14, 15, 16 and 17)

\begin{tabular}{lcccccc}
\hline Treatment & Temperature $\left({ }^{\circ} \mathrm{C}\right)$ & Time $(\mathrm{h})$ & $\mathrm{GO}$ & 14 & 15 & 17 \\
\hline Ungerminated grain & --- & --- & $242.67 \pm 19.19^{\mathrm{a}}{ }_{\mathrm{A}}$ & $311.35 \pm 13.42^{\mathrm{a}}{ }_{\mathrm{C}}$ & $291.71 \pm 11.58^{\mathrm{a}}{ }_{\mathrm{B}}$ & $316.83 \pm 13.29^{\mathrm{a}}{ }_{\mathrm{C}}$ \\
Soaking & 28 & 24 & $262.05 \pm 17.94^{\mathrm{a}}{ }_{\mathrm{A}}$ & $361.50 \pm 9.10^{\mathrm{b}} \mathrm{C}_{\mathrm{C}}$ & $296.24 \pm 12.72^{\mathrm{a}}{ }_{\mathrm{B}}$ & $298.93 \pm 13.65^{\mathrm{a}}{ }_{\mathrm{B}}$ \\
Germination & 28 & 48 & $467.08 \pm 18.11^{\mathrm{b}}{ }_{\mathrm{B}}$ & $467.00 \pm 13.07^{\mathrm{c}}{ }_{\mathrm{B}}$ & $456.95 \pm 12.37^{\mathrm{b}}{ }_{\mathrm{B}}$ & $404.51 \pm 11.04^{\mathrm{b}}{ }_{\mathrm{A}}$ \\
& 28 & 96 & $729.60 \pm 20.87^{\mathrm{d}}{ }_{\mathrm{C}}$ & $674.21 \pm 26.05^{\mathrm{d}}{ }_{\mathrm{B}}$ & $678.09 \pm 18.35^{\mathrm{d}}{ }_{\mathrm{B}}$ & $626.06 \pm 26.57^{\mathrm{d}}{ }_{\mathrm{A}}$ \\
& 34 & 48 & $517.04 \pm 29.95^{\mathrm{c}}{ }_{\mathrm{B}}$ & $479.60 \pm 23.15^{\mathrm{c}}{ }_{\mathrm{A}}$ & $612.25 \pm 24.33^{\mathrm{c}}{ }_{\mathrm{C}}$ & $467.88 \pm 18.04^{\mathrm{c}}{ }_{\mathrm{A}}$ \\
& 34 & 96 & $1054.68 \pm 49.54^{\mathrm{e}}{ }_{\mathrm{C}}$ & $965.12 \pm 20.45_{\mathrm{B}}^{\mathrm{e}}$ & $718.21 \pm 29.80^{\mathrm{e}}{ }_{\mathrm{A}}$ & $681.35 \pm 31.91^{\mathrm{e}}{ }_{\mathrm{A}}$ \\
\hline
\end{tabular}

Data are the mean values \pm standard deviation of three independent experiments $(n=3)$. Different lowercase letters indicate significant difference among mean values within a column ( $\mathrm{P} \leq 0.05$ according to Duncan's test). Different capital letters indicate significant difference among mean values within a row ( $\mathrm{P} \leq 0.05$ according to Duncan’s test). 
Table 4. Predictive multiple linear regression based on the RSM of GABA, TPC and antioxidant activity as measured by ORAC for four germinated Ecuadorian brown rice cultivars (GO, 14, 15 and 17).

\begin{tabular}{|c|c|c|c|c|}
\hline Cultivar & Response & Model & Predicted model & $\overline{\mathrm{R}^{2}}$ \\
\hline \multirow[t]{3}{*}{ GO } & GABA (mg/100g d.m.) & $\begin{array}{l}\text { Quadratic without } \\
\text { interaction }\end{array}$ & $\mathrm{Y}(\mathrm{T}, \mathrm{t})=-34.2647+2.02966 \times \mathrm{t}-0.00649975 \times \mathrm{t}^{2}$ & 0.983 \\
\hline & TPC (mg GAE/100g d.m.) & $\begin{array}{l}\text { Quadratic without } \\
\text { interaction }\end{array}$ & $Y(T, t)=63.9014-0.239681 \times t+0.0146973 \times t^{2}$ & 0.992 \\
\hline & ORAC (mg TE/100g d.m.) & $\begin{array}{l}\text { Quadratic with } \\
\text { interaction }\end{array}$ & $Y(T, t)=794.882-18.7425 \times T-15.7889 \times t+0.544697 \times T \times t+0.0379633 \times t^{2}$ & 0.981 \\
\hline \multirow[t]{3}{*}{14} & GABA (mg/100g d.m.) & Pure linear & $Y(T, t)=-21.5128+1.22664 \times t$ & 0.990 \\
\hline & TPC (mg GAE/100g d.m.) & $\begin{array}{l}\text { Quadratic with } \\
\text { interaction }\end{array}$ & $Y(T, t)=15.0221+2.23525 \times T+0.429252 \times t-0.026276 \times T \times t+0.0113867 \times t^{2}$ & 0.974 \\
\hline & ORAC (mg TE/100g d.m.) & $\begin{array}{l}\text { Quadratic with } \\
\text { interaction }\end{array}$ & $Y(T, t)=1016.9-20.7811 \times T-17.0041 \times t+0.500486 \times T \times t+0.0426264 \times t^{2}$ & 0.960 \\
\hline \multirow[t]{3}{*}{15} & GABA (mg/100g d.m.) & $\begin{array}{l}\text { Quadratic with } \\
\text { interaction }\end{array}$ & $\mathrm{Y}(\mathrm{T}, \mathrm{t})=89.3497-3.3682 \times \mathrm{T}-0.150929 \times \mathrm{t}+0.0356642 \times \mathrm{T} \times \mathrm{t}+0.0023137 \times \mathrm{t}^{2}$ & 0.968 \\
\hline & TPC (mg GAE/100g d.m.) & $\begin{array}{l}\text { Quadratic with } \\
\text { interaction }\end{array}$ & $Y(T, t)=-15.1759+4.29992 \times T+1.14789 \times t-0.0789785 \times T \times t+0.0222498 \times t^{2}$ & 0.977 \\
\hline & ORAC (mg TE/100g d.m.) & $\begin{array}{l}\text { Quadratic with } \\
\text { interaction }\end{array}$ & $\mathrm{Y}(\mathrm{T}, \mathrm{t})=-71.7061+7.09389 \times \mathrm{T}+4.64064 \times \mathrm{t}+0.0622064 \times \mathrm{T} \times \mathrm{t}-0.0167007 \times \mathrm{t}^{2}$ & 0.952 \\
\hline \multirow[t]{3}{*}{17} & GABA (mg/100g d.m.) & $\begin{array}{l}\text { Quadratic with } \\
\text { interaction }\end{array}$ & $Y(T, t)=135.858-4.42264 \times T-0.905722 \times t+0.051392 \times T \times t+0.0024870 \times t^{2}$ & 0.923 \\
\hline & TPC (mg GAE/100g d.m.) & $\begin{array}{l}\text { Quadratic with } \\
\text { interaction }\end{array}$ & $Y(T, t)=-168.016+8.43192 \times T+3.15678 \times t-0.131625 \times T \times t+0.0182717 \times t^{2}$ & 0.948 \\
\hline & ORAC (mg TE/100g d.m.) & $\begin{array}{l}\text { Quadratic with } \\
\text { interaction }\end{array}$ & $Y(T, t)=257.971+0.214647 \times T-1.89938 \times t+0.0928168 \times T \times t+0.0188063 \times t^{2}$ & 0.980 \\
\hline
\end{tabular}

$\mathrm{T}=$ temperature; $\mathrm{t}=$ time 
Figure 1.

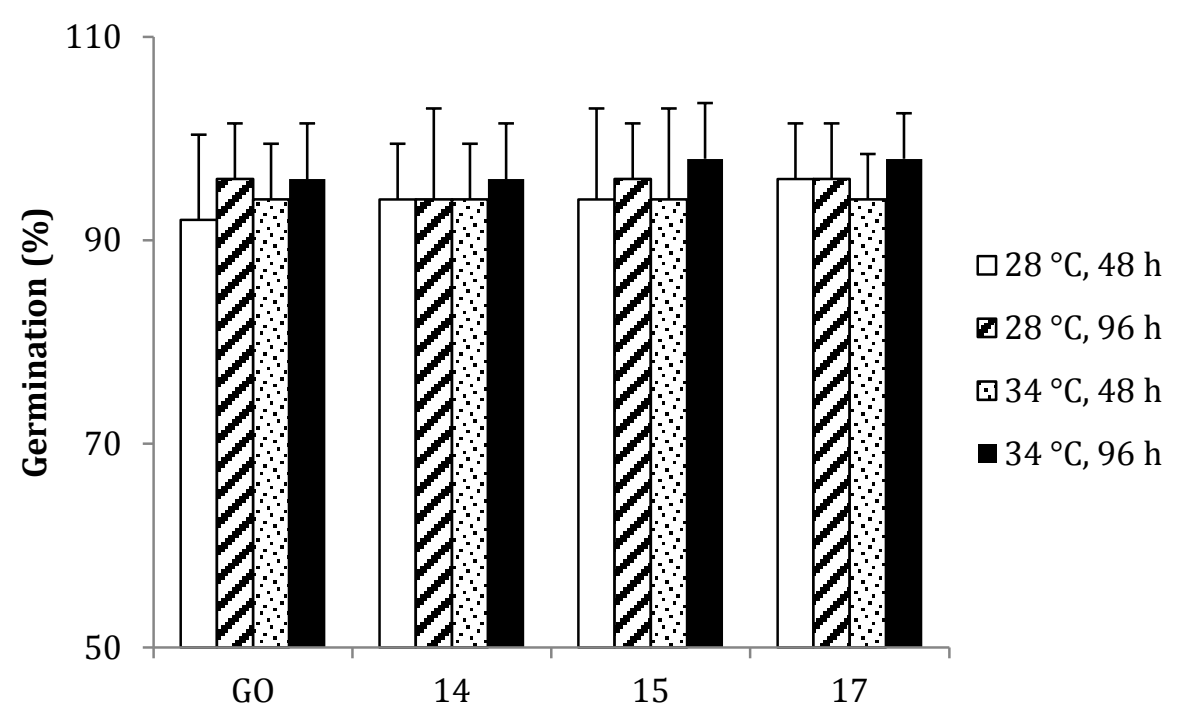

Brown rice cultivar 
Figure 2.

\section{GABA}

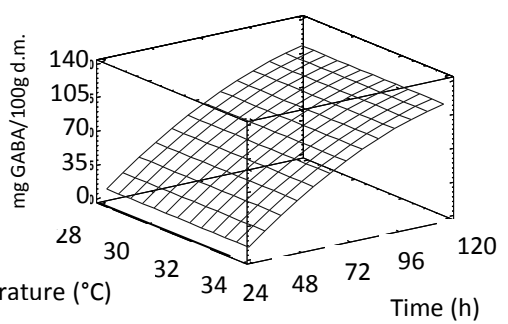

Cv. 14

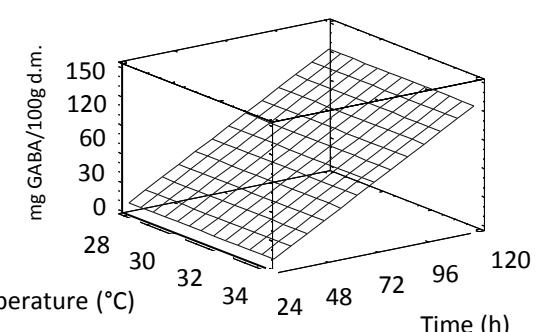

Cv. 15

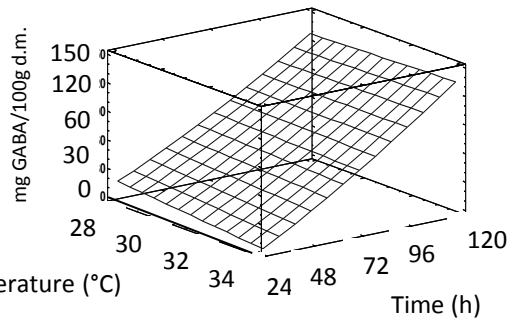

Cv. 17

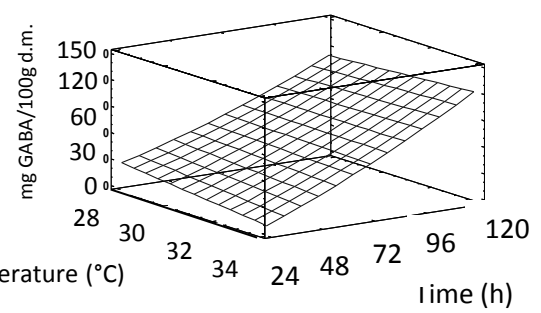

TPC
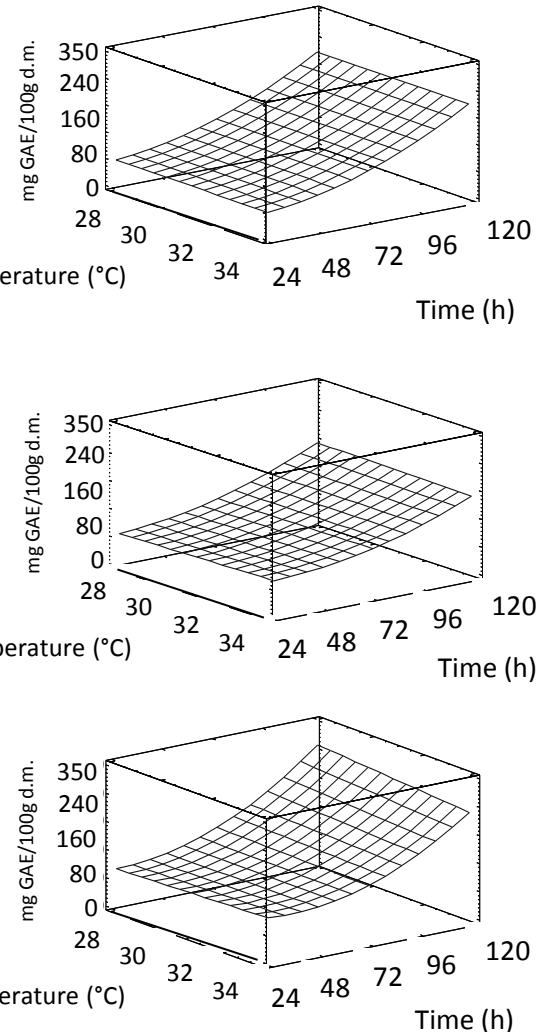

Time (h)

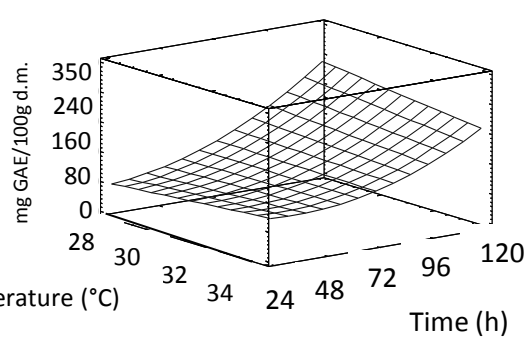

ORAC
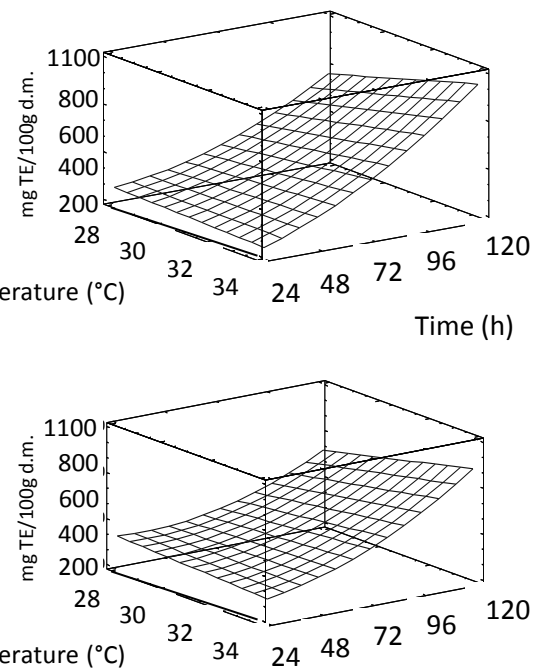

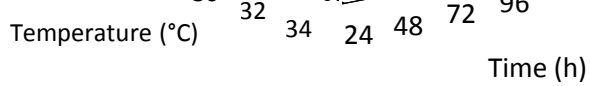
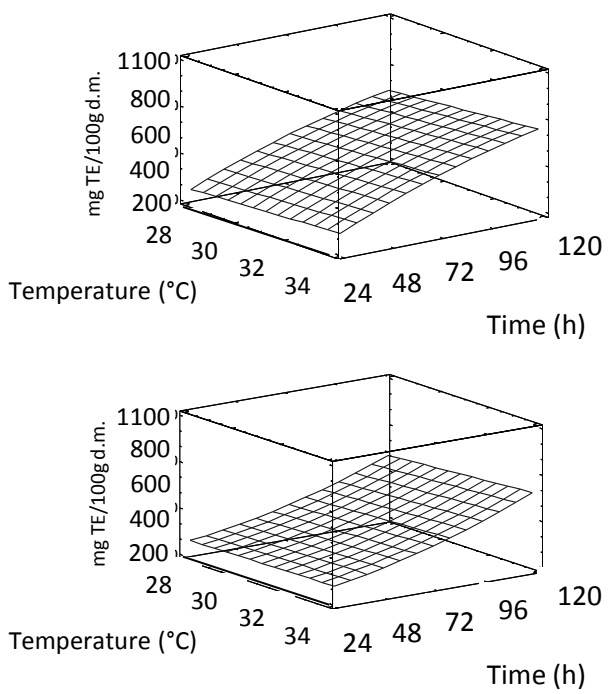
